\title{
BMJ Open Quality Introducing a reserve waiting list initiative for elective general surgery at a District General Hospital
}

\author{
Vaki Antoniou, ${ }^{1}$ Olivia Burke, ${ }^{2}$ Roland Fernandes ${ }^{3}$
}

To cite: Antoniou V, Burke 0, Fernandes R. Introducing a reserve waiting list initiative for elective general surgery at a District General Hospital. BMJ Open Quality 2019;8:e000745. doi:10.1136/ bmjoq-2019-000745

Received 1 June 2019 Revised 1 August 2019 Accepted 5 August 2019

\section{Check for updates}

(c) Author(s) (or their employer(s)) 2019. Re-use permitted under CC BY-NC. No commercial re-use. See rights and permissions. Published by BMJ.

${ }^{1}$ Trauma and Orthopaedics, Lewisham and Greenwich NHS Trust, London, UK

${ }^{2}$ Accident and Emergency, King's College Hospital NHS Foundation Trust, London, UK

${ }^{3}$ General Surgery, William Harvey Hospital, Ashford, UK

Correspondence to

Dr Vaki Antoniou;

v.antoniou@nhs.net

\section{ABSTRACT}

Cancelled operations represent a significant burden on the National Health Service in terms of theatre efficiency, financial implications and lost training opportunities. Moreover, they carry considerable physical and psychological effects to patients and their relatives. Evidence has shown that up to $93 \%$ of cancelled operations are due to patient-related factors. An analysis at our District General Hospital revealed that approximately 18 operations are cancelled on the day of surgery each month. This equates to 27 hours of allocated operating time valued by the trust as $£ 67500$, not being used effectively. This retrospective quality improvement report aims to reduce unused theatre time due to cancelled elective operations in general surgery theatres-thereby improving theatre efficiency and patient care. To ascertain the baseline number of cancelled operations, an initial review of theatre cases was undertaken. Further review was then completed after implementation of two improvements-a short notice surgical waiting list and fast track pre-assessment clinics. The results showed that implementation of the reserve surgical waiting list reduced unused operating time by an average of 2.25 hours per month. By further adding in the fast track preassessment clinic, these figures increased to an average of 11.5 hours over the next 3 months. This precipitated a reutilisation of otherwise wasted theatre time. Economic impact of this time amounts around $£ 28750$ a month, after implementation of both improvements. Simple protocol changes can lead to large improvements in the efficient running of theatres. The resultant change has improved patient satisfaction, led to greater training opportunities and improved theatre efficiency. Extrapolation of our results show better usage of previously underused theatre time, to the equivalent worth of $£ 345000$. Further implementation of these improvements in other surgical specialities and hospitals would be beneficial.

\section{PROBLEM}

Operations cancelled on the day are a frequent but frustrating encounter for National Health Service (NHS) staff and patients. They lead to a significant reduction in theatre efficiency, financial implications for the trust and lost training opportunities. In addition, they carry considerable physical and psychological effects to the patient and their relatives. ${ }^{1}$ Often these operations would need to be rescheduled, further increasing the NHS burden.

At our District General Hospital, approximately 15-20 operations are cancelled on the day of surgery every month. The reasons are wide ranging, from acute patient illness to decision to proceed with an operation being changed. The following quality improvement project was conducted at a District General Hospital in Kent. It serves a population of approximately 500000 patients spanning the south of west Kent and parts of north-east Sussex, with 264 beds. The hospital provides elective operations with emergency operations diverted to an affiliated hospital within the trust.

The problem of missed operations poses an issue for the NHS. We wanted to explore how simple, cost-effective measures could be implemented to improve theatre efficiency in the event of cancellation on the day of surgery. We developed a SMART aim of a reduction in unused theatre time, due to cancelled operations, of $20 \%$ on a per-monthly basis. Unused theatre time is defined as time spent with theatres available (staff and resources) but not utilised. Reduction in unused theatre time was the primary outcome measure with secondary analyses considering percentage of operating time replaced and the economic impact of reallocated operating time.

\section{BACKGROUND}

Theatre inefficiency is a popular topic for quality improvement, with $46 \%$ of patients attending hospital, undergoing an operation. ${ }^{2}$ Inefficiency is defined as a 'wasteful use of resources'. ${ }^{3}$ Quality improvement in healthcare has been stated to involve 'better system performance', 4 while cost-effectiveness is the economic impact of health interventions. ${ }^{5}$ Previous quality improvement articles have focused on cost saving versus cost-effectiveness analysis. ${ }^{6}$ Cost saving is the numerical reduction in spending from improved 
quality, while cost-effectiveness is the maximisation of improvements with the resources available. ${ }^{67}$

Extensive literature has shown that cancelled operations represent a significant burden on healthcare systems. ${ }^{8-12}$ Up to $60 \%$ of cancellations are thought to be avoidable. ${ }^{13}$ NHS England has shown that the number of cancelled elective operations has doubled in the last 15 years ${ }^{14}$. In a separate study, $93 \%$ of operations were cancelled due to patient-related factors, with $7 \%$ cancelled by the hospital. ${ }^{15}$ Specific implicated reasons for cancelled operations include patients being insufficiently prepared for the operation, absenteeism of surgeons/patients and shortage of required equipment. ${ }^{1617}$ One widely accepted reason behind cancellation of elective inpatient lists is the problematic lack of hospital beds. This was found to be the reason of cancellation in 31\%-62\% of elective case postponement/cancellation across one theatre database. ${ }^{18}$

Same day cancellation rates among different units varies considerably. The $6.1 \%-30.3 \%$ of cancelled operations are cancelled on the day of surgery. ${ }^{21719-22}$ Reports show that $9 \%-16 \%$ of same-day cancellations are due to patient non-attendance on the day of the operation without any prior warning. ${ }^{1723}$ One smaller study even showed reports of patient absenteeism of up to $54 \% .^{24}$ Cancellation on the day of surgery can have large socioeconomic implications to both patients and the trust. In cases, the impact can extend beyond the patient to family members and carers, with missed days at work and time and money spent on travelling. ${ }^{2}$

Financial repercussions of cancelled operations can be substantial. In 1 year, the financial loss to the NHS from cancelled operations for one orthopaedic surgeon amounted to $£ 335349 .{ }^{10}$ Another study showed inefficiencies around theatre running equating to an equally large amount of $£ 347327 /$ theatre/year. ${ }^{11}$

Other teams have previously attempted to attend to this problem of cancelled operations. One group achieved promising outcomes through usage of a mobile phone application to improve patient adherence rates among theatre attendees. ${ }^{25}$ In a cohort of 164 patients, all those using the application (85) attended their theatre appointment with the appropriate preoperative workup. Five of the 89 who did not have the application had their operation cancelled, for patient-related reasons. ${ }^{25}$ Video-based technology has also been used to improve surgical cancellation rates. ${ }^{26}$ Other groups found similar success using a preoperative protocol. $^{9}$

Pandit et aldescribed operative efficiency as "maximising utilisation, minimising over-running and minimising cancellations on a list'. ${ }^{27}$ Time wastage specifically has been researched with suggested improvements including usage of experienced surgeons, simultaneously anaesthetising the next scheduled patient and ensuring the patients are called to theatre in a punctual fashion. ${ }^{11} 27$

Reduction in waste of resources for the trust is both important and valuable. The trust allocates a specific budget to run theatres. This includes staff (surgeons, anaesthetists, list coordinators, cleaners, etc) and hardware resources. ${ }^{28} 29$ Much of this cost remains constant. In the instant of cancelled operative lists, money is still spent running theatres. Our project aims to reduce time spent with theatres being run, but not in use, improving theatre efficiency.

Improving quality can lead to both cost effectiveness and savings. Standardising the cardiac bypass operation saved close to half a million dollars over a year. ${ }^{30}$ Review of five quality improvement projects in Sweden also highlighted up to US $\$ 0.6$ million in annual savings. ${ }^{31}$ Immunisation and screening programmes in children are examples of cost-effective interventions. ${ }^{732}$ Quality improvement has been suggested as resolution to the growing financial challenges of the NHS. ${ }^{33}$ Conversely, there is evidence inferring poor quality increases costs. Unplanned hospital readmissions in the USA in 2004 was estimated to cost Medicare US $\$ 17.4$ billion. ${ }^{34}$ Further examples include $25 \%$ of radiographic tests being unnecessary and $4 \%-10 \%$ of UK hospital patients getting pressure sores. ${ }^{35}$ Eliminating inefficiency was attributed to increasing productivity output by $26 \%$ across 1377 hospitals in the USA. ${ }^{36}$

While improving efficiency may not always save money directly, it represents better usage of resources. This highlights the nature of 'soft savings'. In economic terms, hard-savings are tangible monetary reductions in spending. ${ }^{37}$ In the hospital setting, this is reduction of budget expenditure on staff or hardware resources, such as using cheaper prostheses in orthopaedic operations. Soft savings, in contrast, are intangible benefits from improvement. ${ }^{37}$ In this case, reduction of unused operating hours, that is, reduction of time and money wastage. Money spent running theatres is unchanged; however, reduction in hours where the theatres are not operating could lead to a 'soft saving'. Our project attempts to answer the problem of time and money wastage by patient cancellations causing inefficient running of theatres.

\section{Measurement}

In the problem finding phase of the project, data were collected retrospectively by analysing theatre records from general surgery cases over the preceding 3 months. Cases cancelled on the day were further assessed for type of operation and reason for cancellation. On the initiation of change, data collection was then collected in a prospective manner using the same technique.

To calculate our primary outcome, the average time taken for that particular operation was used as a marker for the theatre time lost or spared. From our retrospectively collected data, we found that on average 1.5 hours was a fairly accurate representation of the average length of time lost or spared per operation; 1.5 hours average is similar to the estimated length of these operations by surgeons and anaesthetists. ${ }^{38}$ Our secondary outcomes were percentage of operations being replaced and an economic analysis of the impact. Soft savings to the trust were estimated on the assumption that an hour of theatre time at our District General Hospital equates to $£ 2500$. 
Data were recorded on an excel spreadsheet for comparison across the months.

\section{Design}

This quality improvement recorded two interventions. Prior to improvements being made, 3 months of data collection was undertaken to understand the average number of cancelled operations. The surgical waiting list was introduced in March 2018. The aim of this waiting list was to replace patients that had been cancelled on the day with other patients already on the waiting list at short notice. This intervention relied on finding appropriate patients. It was decided that appropriate patients must fulfil the following criteria:

- Fit for the operation (American Society of Anesthesiologists I/II).

- Undergoing a non-complex operation, not requiring specialist equipment.

- Patient able to attend at short notice.

Examples of suitable operations which could be brought in at short notice include excision of skin lesions, inguinal/ umbilical hernia repairs, examination under anaesthesia anorectum or any simple procedure, operable under local anaesthetic. Certain operations such as laparoscopic cholecystectomy were also potentially suitable as per the discretion of the individual consultant, who ultimately had control over their own individual reserve waiting list of patients. A selection flowchart (figure 1) was created and distributed to help aid doctors choose appropriate patients for this service improvement.

One of the problems noted in the period of MarchJune 2018 was the lack of patients that were available to be brought in at late notice. This prompted addition of a second intervention in June 2018. This was a fast track system for preassessment. The purpose underpinning this was to increase the numbers of available patients on the surgical waiting list and not be limited by the patients being willing to have their operation at short notice but being unable to do so as they had not been preassessed.

\section{Strategy}

The main aim for our project revolved around maximisation of resources. Literature has shown that inefficient usage of theatres can have considerable impacts. Interventions were aimed at reducing inefficiency primarily in terms of theatre time with secondary analysis of the economic impact. The SMART aim for this project was a $20 \%$ reduction in theatre time lost as a consequence of operations cancelled on the day of surgery and no suitable alternative patients being identified.

\section{Phase 1}

Initial data was recorded over the period of JanuaryMarch 2018. This was a problem-identifying step to ascertain number of cancelled operations each month. We then implemented change in the form of selecting suitable patients in the preoperative clinic to add to our 'surgical waiting list'. An algorithm illustrating how suitable patients were found is shown in figure 1 . This intervention led to an unused theatre time reduction of 8.3\%; an average 2.25 hours per month. When we began in April, one main problem was that although cancellations were ongoing, there was a lack of patients that had been preassessed. This reduced the number of patients available to come in at short notice.

\section{Phase 2}

To rectify the issue noted of a shortfall in preassessed patients, a fast track system of preassessment was implemented. This meant otherwise fit and healthy patients were seen quicker from the decision being made that they needed surgery. Suitable patients were identified sooner, increasing list numbers, therefore increasing the pool of patients available to attend surgery at short notice.

In designing this project, identification of a suitable team for running the process was the initial step. A challenge was finding a specialty with suitable operations whereby patients may accommodate operating gaps. General surgery run elective lists daily with numerous clinics happening throughout the week. Additionally, with the throughput of patients from emergency department, there is high turnover of patients presenting surgical conditions that require surgery, not through an emergency pathway. Operations on the list should not be long or complex and common enough to provide an adequate patient population for the list. Other specialties that were discussed for this project include urology and otolaryngology, both of which have non-emergent, quick operations. Next was formation of a team to run the project. This comprised two doctors overseen by a senior, responsible for formulation of a plan, deadlines and analysis of data. One of the most important jobs was management of the list itself. One of the theatre coordinators took on this role as 'waiting-list coordinator' which worked well, given the nature of her job. We anticipated that we may need to adjust roles throughout the project; however, this was not necessary.

As with any process, challenges were encountered. Patients did not always answer their phone or became non-adherent to the presurgery plan. A specific example of this was a man who persistently ate breakfast at 09:00. Another problem that arose was that someone turned up the day after clinic to accident and emergency as he did not quite understand the instructions. For those involved with planning of a similar project in future, we recommend formulation of booklets for patients to read in their own time, detailing the nature of the project.

We originally had concerns with the fast track clinics regarding increasing workloads. However, while appearing to require more resources, patients seen did not require additional consultation following being seen. All of the consultant body at the hospital agreed to be involved with the project, namely with involvement in the fast track clinics and also isolating eligible patients for our list. 


\section{Algorithm for The Reserve General Surgery Waiting List}

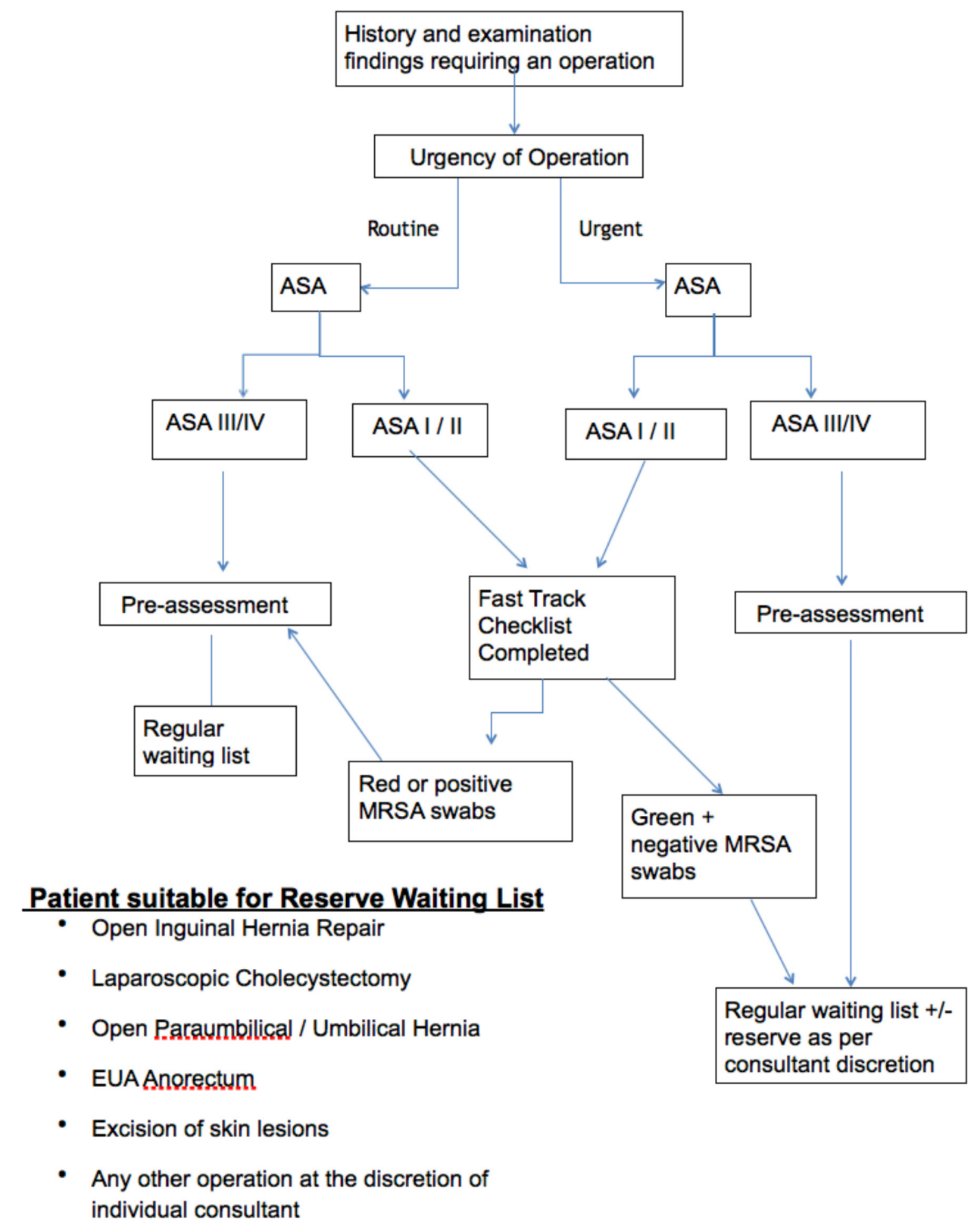

Figure 1 The algorithm used for selection of appropriate patients for the surgical reserve list. ASA, American Society of Anesthesiologists; EUA, Examination Under Anaesthesia; MRSA, methicillin-resistant Staphylococcus aureus.

\section{RESULTS}

The primary outcome measure was unused theatre time and specifically how it had been reduced by our interventions. We also analysed a monetary representation of the theatre time replaced.

All the data have been compiled accurately from the theatre data on a daily basis. Data analysed were therefore complete, with no gaps or missing data. Acquisition of results went to plan with no unexpected changes. There were some patients that were not contactable on the day of an unforeseen cancellation. This was something that had been anticipated.
The vast majority of the data that we collected demonstrated that the operations were cancelled due to being unsuitable, a change in clinical status of the patient (ie, the patient was ill on the day) or a change in the choice of the patient.

Before any intervention had been conducted, from January 2018 to March 2018, there was an average of 27 theatre hours unused per month due to cancelled operations. After the first improvement of the addition of the reserve surgical list, there was once more an average of 27 unused hours in theatres. However, three patients over the 2 months of recording were brought back for operations 
to fill gaps. This represented an average of 2.25 hours efficiently reallocated per month, or a $8.3 \%$ improvement. As has been previously alluded to, we noted that there was an issue with the low number of patients available on the surgical reserve list. This led to the implementation of our second intervention.

After the second cycle, in which patients were fast tracked for preassessment, allowing a larger number of patients on the surgical reserve list, we noted further improvement. Once again, the average unused theatre hours due to cancelled operations was 27. This time, however, an increased number of patients were able to be brought in at short notice, amounting to 11.5 hours reallocated, on average, per month. This accumulated to a $42.6 \%$ improvement, which is over double our SMART aim of $20 \%$ improvement.

If this data were to be extrapolated, the annual reduction in wasted theatre hours at our District General Hospital would amount approximately 138, valued at $£ 345000$ per annum. The results of our interventions are graphically depicted in figure 2 .
Longevity of results and improvement is dependent on sustainability. Our project was over an 8 months span in a general surgical department at a district general hospital. Since completion of the project, there has been continuation of the reserve list and fast track clinics, with good results. The next stage is expanding the project throughout further surgical specialities including urology and otolaryngology. Certainly particular specialities and operations may convey better suitability to a reserve list than others. It remains to be seen whether the same format can be applied elsewhere. However, there is no clear reason to believe that our strategy would not be effectual at other hospitals. In order to enable uptake in other teams and hospitals, involvement of multidisciplinary members is necessary.

\section{Lessons and limitations}

Our results show that the initiation of a simple intervention has led to significant and marked improvements in the efficiency of elective operating theatres. Reflection of the methodology, results and process of the project has led to a number of points worthy of discussion.

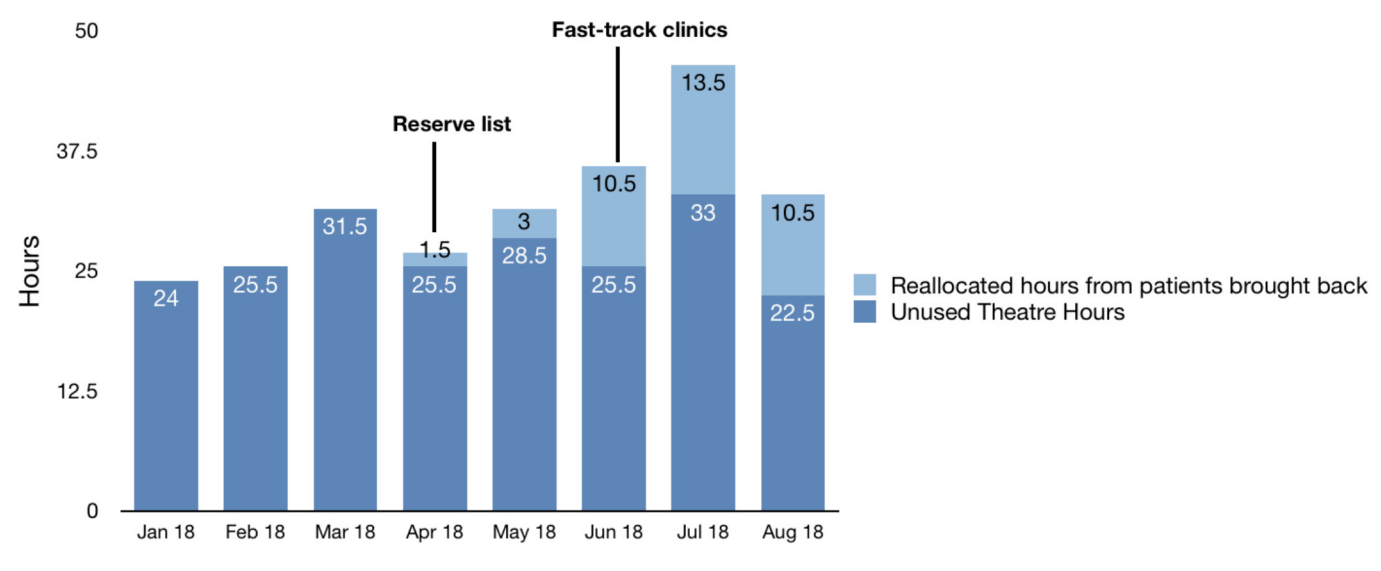

$£ 30,000.00$

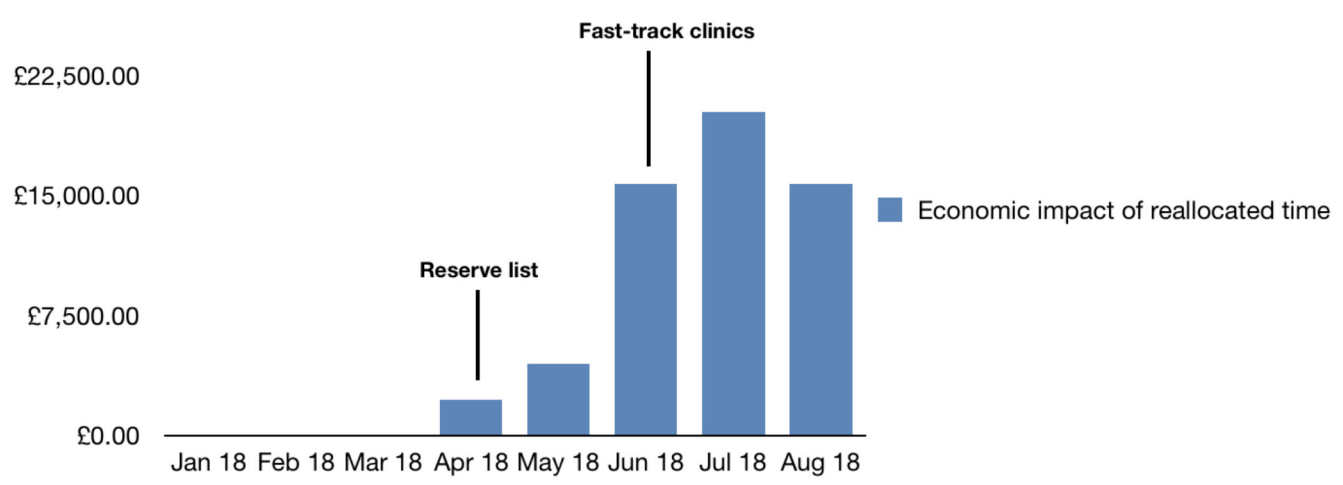

Figure 2 Graphical depictions of the unused and reallocated theatre hours $(A)$ and economic impact $(B)$ following the introduction of both the surgical reserve list and the fast track preassessment clinics. (A) Graph showing unused theatre hours from patient cancellations and the number of reallocated hours following our interventions. (B) Graph showing the economic impact of reallocated theatre hours, based upon the assumption that 1 hour of theatre time is worth £2500. 
We faced many challenges throughout the improvement process. One of the most important steps of this project was finding appropriate patients for the surgical reserve list. Patients are unique, and it is often difficult to have universal rules that apply globally. A large proportion of the demographic data was omitted when choosing appropriate patients for the surgical reserve list, for this reason. Criteria such as age were left to the discretion of the consultant in ownership of their individual list.

Being on the surgical reserve list may also require patients to change daily routine. For example, those patients hoping to be called in on the same day to fill an empty slot, would be required to be close to the hospital to enable admission at short notice, as well as having eaten before 08:00.

Another limitation that became apparent through the latter months of data collection was giving patients false hope of a faster operation. Despite patients being adequately counselled that being placed on the reserve list may not actually bring forward their date of operation, on occasion patients maintained this expectation. The team found particular difficulty with elimination of these assumptions at times. Moreover, there are psychological impacts for patients who are on the list. Increased anxiety or apprehension could arise on the particular days of the week in which they were informed a call might occur.

Managing the size of the list to an appropriate number is not only fundamental but also challenging to ensure that this quality improvement is sustainable. Our data showed that just by increasing the numbers of patients on the reserve list, the average number of reallocated hours rose from 2.25 to 11.5 per month. This was the biggest development seen during the project and reflected an analysis of the data and assessment of the limitations of the initial change. Towards the end of the project, we were beginning to see the opposite effect, whereby increased numbers of patients, appropriate for the list were being isolated. However, there was insufficient scope for further additions to the list, due to the already large population in reserve.

Another factor pivotal to the success of the project was communication with the patient. As mentioned earlier, there were times that the patient was uncontactable. This is something that was anticipated at the start of the project, with all patients added to the list briefed that they should be available by phone. Telephone communication seems the best way to contact patients in this case and, in fact, other mechanisms such as email or postal mail would be inappropriate, due to time constraints.

The system of having a waiting list coordinator is one that is shared among many other hospitals throughout the UK. For this reason, it is a reproducible project and one that could have impacts on other hospitals nationally. Another factor to note is that this system had a relatively small sample size of the general surgery theatre lists. This small sample size affected our results and larger studies are required to improve the validity of our conclusions prior to implementation of similar systems in other hospitals, or on other specialities. One suggestion for this would be to apply a similar system across all the surgical specialities in the same hospital, to increase the number of patients operated on a daily basis.

Another issue that became apparent from the background literature is that the reasons behind cancelled operations are multifactorial. From lack of bed spaces to change in clinical status, there are many reasons why operations may need to be delayed or cancelled altogether. ${ }^{13} 18$ This study aimed to counteract one aspect, however, in order to truly optimise the efficiency of theatre time and running, a combinatory approach should be taken, whereby different facets are accounted for.

\section{CONCLUSION}

In summary, this was a project conducted over 8 months examining general surgery elective operations at a local District General Hospital. It was able to reaffirm an issue previously discussed by others namely inefficient theatre usage, with resultant financial, socioeconomic and training implications posed thereof. Creation of a patient reserve list, managed by a waiting list coordinator, consisting of up to 10 patients under each lead consultant, was completed. If an operation was cancelled, a patient may be brought in at short notice for appropriate use of valuable resources.

The benefits evidenced by this project included better allocation of resources at a time where both the trust and NHS are under pressure both financially and with training opportunities. Our results showed that implementation of simple improvement measures was able to make a $42.6 \%$ reduction in theatre resource inefficiency. This reduction in inefficiency led to reallocation of theatre hours, to the annual value of $£ 345000$. Our project, despite only focusing on a small number of patients, certainly shows a significant impact, as well as being a sustainable option for future. However, attaining data across other hospitals and specialities would give a truer representation of the impact on time and finances. Another lesson learnt was that in order to account for the multifactorial reasons behind cancelled operations, combined approaches to improve both patient and hospital efficiency are likely to be the most successful.

All in all, this was a successful project, which was able to surpass the original smart aim of a $20 \%$ reduction in unused time from cancelled operations.

Contributors VA was responsible for compilation and reporting of the work in this article. VA is also responsible for the overall content as guarantor. OB was responsible for data collection and conducting the audit. RF was responsible for planning and overseeing the project.

Funding The authors have not declared a specific grant for this research from any funding agency in the public, commercial or not-for-profit sectors.

Competing interests None declared.

Patient consent for publication Not required.

Provenance and peer review Not commissioned; internally peer reviewed.

Open access This is an open access article distributed in accordance with the Creative Commons Attribution Non Commercial (CC BY-NC 4.0) license, which 
permits others to distribute, remix, adapt, build upon this work non-commercially, and license their derivative works on different terms, provided the original work is properly cited, appropriate credit is given, any changes made indicated, and the use is non-commercial. See: http://creativecommons.org/licenses/by-nc/4.0/.

\section{REFERENCES}

1. Tait AR, Voepel-Lewis T, Munro HM, et al. Cancellation of pediatric outpatient surgery: economic and emotional implications for patients and their families. J Clin Anesth 1997;9:213-9.

2. Gordon T, Paul S, Lyles A, et al. Surgical unit time utilization review: resource utilization and management implications. J Med Syst 1988;12:169-79.

3. Severens JL. Value for money of changing healthcare services? economic evaluation of quality improvement. Qual Saf Health Care 2003;12:366-71.

4. Batalden PB, Davidoff F. What is quality and safety in health care 2007;16.

5. Maciosek MV, Coffield AB, Edwards NM, et al. Prioritizing clinical preventive services: a review and framework with implications for community preventive services. Annu Rev Public Health 2009;30:341-55

6. Grosse SD. Does newborn screening save money? the difference between cost-effective and cost-saving interventions. J Pediatr 2005;146:168-70.

7. Doubilet $P$, Weinstein MC, McNeil BJ. Use and misuse of the term "cost effective" in medicine. N Engl J Med 1986;314:253-6.

8. Lacqua MJ, Evans JT. Cancelled elective surgery: an evaluation. Am Surg 1994;60:809-11.

9. Turunen E, Miettinen M, Setälä L, et al. The impact of a structured preoperative protocol on day of surgery cancellations. J Clin Nurs 2018;27:288-305

10. Arshad MS, Majeed T, Shah N, et al. Elective list cancellations and its financial ramifications. J Perioper Pract 2019;29:24-6.

11. Ang WW, Sabharwal S, Bhattacharya R, et al. The cost of trauma operating theatre inefficiency. Int J Surg 2016;36.

12. Appavu ST, Al-Shekaili SM, Al-Sharif AM, et al. The burden of surgical cancellations and No-Shows: quality management study from a large regional hospital in Oman. Sultan Qaboos Univ Med J 2016;16:e298-302.

13. Schofield W, Rubin G, Piza M, et al. Cancellation of operations on the day of intended surgery at a major Australian referral hospital, 2005. Available: https://onlinelibrary.wiley.com/doi/abs/10.5694/j.13265377.2005.tb06846.x

14. S. Statistics » Cancelled Elective Operations [Internet]. Available: https://www.england.nhs.uk/statistics/statistical-work-areas/ cancelled-elective-operations/ [Accessed 22 Apr 2019].

15. Cho H-S, Lee $\mathrm{Y}$, Lee $\mathrm{S}$, et al. Reasons for surgery cancellation in a general Hospital: a 10-year study. Int $J$ Environ Res Public Health;16:7.

16. Windokun A, Obideyi A. Audit of emergency theatre utilisation. Afr J Med Med Sci 2001:59-2.

17. Garg R, Bhalotra AR, Bhadoria P, et al. Reasons for cancellation of cases on the day of surgery-a prospective study. Indian J Anaesth 2009;53:35-9.

18. Robb WB, O'Sullivan MJ, Brannigan AE, et al. Are elective surgical operations cancelled due to increasing medical admissions? Ir J Med Sci 2004;173:129-32.
19. Macarthur AJ, Macarthur C, Bevan JC. Determinants of pediatric day surgery cancellation. J Clin Epidemiol 1995;48:485-9.

20. Guyuron B, Zarandy S. Causes for cancellation of aesthetic and reconstructive procedures. Plast Reconstr Surg 1993;92:662-8.

21. Turunen E, Miettinen M, Setälä L, et al. Elective surgery cancellations during the time between scheduling and operation. J Perianesth Nurs 2019;34:97-107.

22. Roxbury CR, Shah J, Tang D, et al. Analysis of 24-hour surgical cancellations in an academic rhinology and skull base surgery practice. Int Forum Allergy Rhinol 2019;9:298-304.

23. Jonnalagadda R, Walrond ER, Hariharan S, et al. Evaluation of the reasons for cancellations and delays of surgical procedures in a developing country. Int J Clin Pract 2005;59:716-20.

24. Paschoal MLH, Gatto MAF. Taxa de suspensão de cirurgia em Um Hospital universitário E OS motivos de absenteísmo do paciente à cirurgia programada. Rev Lat Am Enfermagem 2006;14:48-53.

25. Stewart JJ, Fayed I, Henault S, et al. Use of a smartphone application for spine surgery improves patient adherence with preoperative instructions and decreases Last-minute surgery cancellations. Cureus 2019;11.

26. Hsieh* T-C, Gross M, Tapscott A, et al. MP27-11 A novel videobased patient education program to reduce penile prosthetic surgery cancellations. J Urol 2019;201(Supplement 4).

27. Pandit JJ, Westbury S, Pandit M. The concept of surgical operating list 'efficiency': a formula to describe the term. Anaesthesia 2007;62:895-903.

28. Luks FI, Logan J, Breuer CK, et al. Cost-Effectiveness of laparoscopy in children. Arch Pediatr Adolesc Med 1999;153.

29. Macario A, Vitez TS, Dunn B, et al. Where are the costs in perioperative care? analysis of hospital costs and charges for inpatient surgical care. Survey of Anesthesiology 1996;40.

30. Øvretveit J. Does improving quality save money? A review of evidence of which improvements to quality reduce costs to health service providers. London: The Health Foundation, 2009.

31. Øvretveit J. The economics of quality - a practical approach. Int J Health Care Qual Assur 2000;13:200-7.

32. Briss PA, Rodewald LE, Hinman AR, et al. Reviews of evidence regarding interventions to improve vaccination coverage in children, adolescents, and adults. The task force on community preventive services. Am J Prev Med 2000;18(1 Suppl):97-140.

33. Marshall M, Øvretveit J. Can we save money by improving quality? BMJ Qual Saf 2011;20:293-6.

34. Jencks SF, Williams MV, Coleman EA. Rehospitalizations among patients in the Medicare fee-for-service program. J Vasc Surg 2009;50:234.

35. Øvretveit J, Tolf S. The costs of poor quality and adverse events in health care - A review of research for the Swedish healthcare compensation insurance company (Landstingens Omsesidiga Forsakringsbolag (LoF. 6, 2009

36. Valdmanis VG, Rosko MD, Mutter RL. Hospital quality, efficiency, and input Slack differentials. Health Serv Res 2008;43:1830-48.

37. Hard And Soft Savings: What Counts Can Be Counted | ISixSigma [Internet]. ISixSigma. Available: https://www.isixsigma.com/ implementation/financial-analysis/hard-and-soft-savings-whatcounts-can-be-counted/ [Accessed 30 Jul 2019].

38. Pandit JJ, Carey A. Estimating the duration of common elective operations: implications for operating list management. Anaesthesia 2006;61:768-76. 